INVENTORY:Jurnal Akuntansi

ISSN 2597-7202 (Print); ISSN 2613-912X (Online)

Vol. 5, No. 2, Oktober 2021, Hal 80-86

Tersedia Online: http://e-journal.unipma.ac.id/index.php/inventory

\title{
Dampak Moderasi Profitabilitas Terhadap Pengaruh CSR, GCG dan Intelectual Capital Terhadap Nilai Perusahaan
}

\author{
Putri Ayunisari ${ }^{1}$, Aristha Purwanthari Sawitri ${ }^{2 *}$ \\ Prodi Akuntansi, Universitas PGRI Adi Buana Surabaya, Indonesia.

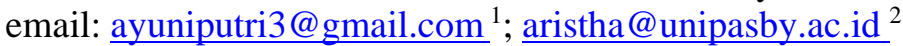

\begin{abstract}
Abstrak
Makna dilakukan penelitian untuk memahami dampak CSR, GCG menggunakan kepemilikan institusional serta IC atas nilai perusahaan menggunakan PBV dengan profitabilitas menggunakan ROE sebagai moderasi. Terdapat 14 sampel perusahaan selama enam tahun penelitian menggunakan cara untuk mengambil sampel dengan metode purposive sampling. Metode analisis menggunakan analisis regresi berganda serta moderated regression analysis yang dibantu dengan software SPSS for Windows 25.00. Hasil penelitian secara parsial menunjukkan tidak adanya pengaruh variabel CSR terhadap PBV, variabel GCG menggunakan kepemilikan institusional menunjukkan berpengaruh positif terhadap PBV, variabel IC menunjukkan tidak adanya pengaruh terhadap PBV, variabel interaksi ROE dengan CSR tidak mampu memoderasi terhadap PBV, variabel interaksi ROE dengan GCG berpengaruh signifikan terhadap PBV yang berati ROE adalah variabel moderasi yang berhasil memperkuat kaitan antara GCG terhadap PBV, dan variabel interaksi ROE dengan IC tidak mampu memoderasi terhadap PBV.
\end{abstract}

Kata Kunci : CSR; GCG; IC; ROE; Nilai Perusahaan

The Impact of Profitability Moderation on the Effect of CSR, GCG, and Intellectual Capital on Company Value

\begin{abstract}
The meaning of the research to understand the impact of CSR, GCG using institutional ownership and IC on value company using PBV with profitability using ROE as moderation. Obtained 14 company samples during the six years of research using a way to take samples by purposive sampling method. The analytical method uses multiple regression analysis and moderated regression analysis provided with SPSS software for Windows 25.00. The results of the partial study showed there was no influence of CSR variables on PBV, GCG variables using institutional ownership showed a positive relati'onship with $P B V$, IC variables showed no influence on PBV, ROE variables with CSR could not moderate towards PBV, ROE variables with $G C G$ were significantly different $P B V$ which means $R O E$ is a moderating variable that succeeds in agreeing between GCG against $P B V$, and the ROE and IC interaction variable is not able to moderate against $P B V$.
\end{abstract}

Keywords: CSR; GCG; IC; firm value

\section{PENDAHULUAN}

DOI: 10.25273/inventory.v5vi2i.8910

Copyright $\odot 2021$ Penulis

Sume rights reserved. 
Peningkatan nilai perusahaan ditentukan oleh kebijakan manajemen serta pemilik. Penentuan kebijakan manajemen dan pemilik perusahaan tidak terlepas dari permasalahan keagenan sehingga diperlukan penerapan corporate governance. Corporate governance dapat mengatur dan mengendalikan manajemen (agen) untuk memfokuskan kepentingan semua pihak (manajemen dan pemegang saham). Kegagalan penningkatan nilai perusahaan, disebabkan permasalahan keagenan yang tidak terselesaikan (Jensen dan Meckling, 1976).

Kesadaran perusahaan terkait dengan lingkungan dapat diinformasikan ke principal melalui pelaporan CSR. Manajemen memastikan kepada principal bahwa kegiatan bisnis yang dilakukan mengutamakan perolehan keuntungan (laba) dan mengutamakan pengelolaan lingkungan untuk kelangsungan hidup jangka panjang perusahaan. Melalui pengelolaan lingkungan, manajemen menunjukkan bahwa dana perusahaan telah dikelola secara efektif dan efisien serta manajemen telah bertindak baik untuk kepentingan perusahaan. Keuntungan perusahaan digunakan manajemen untuk kepentingan lingkungan sebagai bentuk tanggung jawab terhadap lingkungan. Pelaksanaan CSR oleh manajemen tergantung pada besarnya keuntungan yang diperoleh perusahaan dan penilaian stakeholders akan meningkat seiring dengan banyaknya kegiatan CSR yang dilakukan manajemen.

Manajemen berupaya semaksimal mungkin untuk mengelola asset yang dimiliki. Sumber daya manusia yang ada di perusahaan merupakan asset yang harus dikelola oleh manajemen. Intellectual capital (IC) merupakan faktor yang dapat memberikan keunggulan kompetitif dalam peningkatan nilai perusahaan. Intelectual Capital yang terdiri dari modal manusia (human capital), modal struktur (structur capital) dan modal pelanggan (customer capital) merupakan asset tidak berwujud yang dimiliki perusahahaan dan merupakan nilai yang sangat berharga, sulit ditiru, langka dan sulit untuk disubstitusikan dengan yang lainnya. Kondisi entitas yang menguntungkan (profitable) yang ditunjukkan dari modal yang kuat, menjadi penilaian stakeholders dan dapat membantu entitas memperoleh pendanaan dari pihak eksternal. Dengan demikian profitabilitas diduga dapat memediasi hubungan antara Corporate Social Responsibility (CSR), Good Corporate Governance (GCG), dan Intellectual Capital (IC) terhadap nilai perusahaan. tingkat profitabilitas yang tinggi akan membuat investor tertarik untuk menanamkan modal ke perusahaan karena peningkatan profitabilitas mengakibatkan return investor meningkat. Respon investor melalui meningkatnya harga saham dan nilai perusahaan juga akan meningkat.

Berbagai penelitian menyimpulkan bahwa terdapat banyak faktor yang mempengaruhi nilai suatu perusahaan seperti yang diangkat oleh beberapa peneliti diantaranya Nurhayati, Poerwati, dan Kartika (2019), Ariani dan Riana (2018), Mariani dan Suryani (2018), Juwita dan Aurora (2016) ditemukan hasil yang masih berbeda-beda sehingga perlu diperlukan penelitian kembali. Penelitian ini bertujuan untuk meneliti efek moderasi profitabilitas pada pengaruh corporate social responsibility, intelectual capital dan good corporate governance terhadap nilai perusahaan.

\section{METODE PENELITIAN}

Jenis penelitian ini adalah Kuantitatif. Populasi yang diambil oleh peneliti seluruh perusahaan yang telah terdaftar di index saham JII selama periode 2013-2018. Kriteria sampel penelitian ini adalah perusahaan yang telah terdaftar di index saham JII periode 2013-2018, perusahaan menerbitkan annual report dan sustansibility report secara rutin pada periode 2013 2018 dan mempublikasikannya di situs resmi BEI serta situs resmi perusahaan, laporan keuangan dalam mata uang rupiah.

\section{VARIABEL DAN PENGUKURAN}

Nilai perusahaan merupakan nilai yang dapat mempengaruhi perusahaan apabila perusahaan tersebut dijual dan dapat menggambarkan seberapa baik atau buruk manajemen mengelola kekayaannya. Nilai perusahaan diproksikan dengan Price Book Value (PBV). Menurut Hadiwijaya (2013) PBV merupakan perbandingan antara harga pasar per saham 
dengan nilai buku suatu perusahaan. Rumus yang digunakan dalam penelitian ini adalah sebagai berikut :

$$
\mathrm{PBV}=\frac{\text { Harga Pasar Saham per Lembar }}{\text { Nilai Buku per Lembar Saham }}
$$

CSR atau sering disebut dengan tanggung jawab sosial perusahaan merupakan rasio yang dihitung dengan menggunakan indikator GRI.G4. yang mana dalam indikator tersebut terdapat 91 (Sembilan Puluh Satu) indikator-indikator yang terkandung dalam penilaian CSR di perusahaan.

$$
\text { CSRI }=\frac{n}{K}
$$

Keterangan :

CSRI : Corporate Social Responsibility Index

$\mathrm{N} \quad$ : Jumlah item pengungkapan CSR yang dipenuhi

K : Jumlah semua item pengungkapan CSR (91 item)

GCG atau dapat diartikan sebagai tata kelola perusahaan yang baik merupakan suatu sistem yang mengatur hubungan antara berbagai pihak yang kepentingan (stakeholders) demi tercapainya tujuan perusahaan (Novita, 2018:38). Semakin tinggi nilai GCG yang didapatkan perusahaan maka akan membuat nilai perusahaan semakin baik dan dapat membuat harga saham mahal serta dapat menarik perhatian para investor untuk menanamkan sahamnya diperusahaan. Dalam penelitian ini GCG diproksikan dengan Kepemilikan Institusional. Kepemilikan Institusional merupakan perbandingan antara saham yang dimiliki oleh pihak institusi dengan saham yang beredar suatu perusahaan.

\section{INST $\quad=\quad \underline{\text { Jumlah Saham Institusi }}$ Jumlah Saham Beredar $\quad$ X 100}

Intellectual Capital (IC) merupakan pengetahuan yang memberikan informasi tentang nilai tak berwujud perusahaan yang dapat mempengaruhi daya tahan dan keunggulan bersaing, Hadiwijaya (2013:19). Pengukuran intellectual capital menggunakan VAICTM, yang merupakan alat mengukur dan memantau kinerja perusahaan yang ditunjukkan oleh human capital, efisiensi struktural modal, dan customer capital. Perhitungan IC (Indrawati,2019) adalah sebagai berikut :

$$
\text { VAICTM }=\text { VAHU+VASC }+ \text { VACA }
$$

Keterangan :

VAICTM : Value Added Intellectual Capital (Nilai Tambah Modal Intelektual)

VAHU : Value Added Human Capital (Nilai Tambah Modal Manusia)

VASC : Value Added Structural Capital (Nilai Tambah Struktur Modal)

VACA : Value Added Capital Employed (Nilai Tambah Modal yang digunakan)

Profitabilitas merupakan kemampuan perusahaan memperoleh laba dalam hubungannya dengan penjualan, total aktiva, maupun modal sendiri, Sartono (2010:122) dalam Cahyani (2019). Profitabilitas merupakan rasio yang akan dihitung menggunakan Return On Equity (ROE) yaitu dengan membagi antara total laba bersih dengan total ekuitas perusahaan. Rumus 
yang digunakan dalam penelitian ini adalah sebagai berikut :

$$
\text { Return On Equity }=\frac{\text { Laba Bersih }}{\text { Total Ekuitas }}
$$

\section{HASIL DAN PEMBAHASAN}

Berikut adalah hasil pengujian yang telah dilakukan oleh peneliti :

\begin{tabular}{lccc}
\hline $\begin{array}{c}\text { Variabe } \\
\mathbf{l}\end{array}$ & $\begin{array}{c}\text { Asymp.Sig.(2- } \\
\text { tailed) }\end{array}$ & Kriteria & Keterangan \\
$\begin{array}{l}\text { Residua } \\
\mathbf{l}\end{array}$ & 0,200 & $0,05 \quad$ Normal \\
\hline \multicolumn{2}{c}{ Sumber : Output SPSS Versi 25 (data diolah) } \\
Gambar 3. Hasil Uji Normalitas
\end{tabular}

\begin{tabular}{lccc}
\hline \multicolumn{1}{c}{ Variabel } & Nilai t & Sig. & \multicolumn{1}{c}{ Keterangan } \\
SQRT_CSR & 0,256 & 0,799 & Bebas Heterokesdatisitas \\
SQRT_GCG & $-0,174$ & 0,862 & Bebas Heterokesdatisitas \\
SQRT_IC & 1,038 & 0,303 & Bebas Heterokesdatisitas \\
SQRT_PROFIT & 0,743 & 0,460 & Bebas Heterokesdatisitas \\
\hline \multicolumn{4}{c}{ Sumber : Output SPSS Versi 25 (data diolah) } \\
\multicolumn{4}{c}{ Gambar 4. Hasil Uji Heteroskedastisitas }
\end{tabular}

\begin{tabular}{llll}
\hline \multicolumn{1}{c}{ Variabel } & \multicolumn{1}{c}{ Tolerance } & VIF & \multicolumn{1}{c}{ Keterangan } \\
SQRT_CSR & 0,879 & 1,138 & Bebas Multikoliniearitas \\
SQRT_GCG & 0,720 & 1,390 & Bebas Multikoliniearitas \\
SQRT_IC & 0,932 & 1,073 & Bebas Multikoliniearitas \\
SQRT_PROFIT & 0,816 & 1,226 & Bebas Multikoliniearitas \\
\hline \multicolumn{4}{c}{ Sumber : Output SPSS Versi 25 (data diolah) } \\
Gambar 5. Hasil Uji Multikolinieritas
\end{tabular}

\begin{tabular}{cccc}
\hline Variabel & $\begin{array}{c}\text { Asymp. Sig } \\
\text { (2.tailed) } \\
\text { Residual }\end{array}$ & Kriteria & Keterangan \\
& 0,272 & $\mathrm{P}>0,05$ & $\begin{array}{l}\text { Tidak terjadi } \\
\text { autokorelasi }\end{array}$ \\
\hline
\end{tabular}

Sumber : Output SPSS Versi 25 (data diolah)

Gambar 6. Hasil Uji Autokorelasi

Model Unstandardized T $\quad$ Sig.




\begin{tabular}{lcll}
\hline \multicolumn{5}{c}{ Coefficients } \\
B \\
(Constant) & $-3,322$ & \\
SQRT_CSR & $-0,755$ & $-0,671$ & 0,504 \\
SQRT_GCG & 0,747 & 3,752 & 0,000 \\
SQRT_IC & $-5,096$ & $-0,191$ & 0,849 \\
\hline
\end{tabular}

\section{Sumber : Output SPSS Versi 25 (data diolah)}

\section{Gambar 7. Hasil Uji Regresi Berganda}

Berdasarkan Gambar 7 dapat dibuat persamaan regresi sebagai berikut :

$$
\mathrm{Y}=-3,322-0,755 \mathrm{X}_{1}+0,747 \mathrm{X}_{2}-5,096 \mathrm{X}_{3}+\mathrm{e}
$$

Uji statistic $\left(\mathrm{H}_{1}\right)$ menghasilkan nilai signifikansi pada variabel CSR sebesar 0,504 >0,05. Nilai tersebut menunjukkan CSR tidak berpengaruh signifikan terhadap. Kenaikan nilai perusahaan tidak dipengaruhi oleh hasil pengungkapan CSR, karena faktor tingkat keuangan perusahaan lebih difokuskan oleh manajemen dibandingkan kepedulian perusahaan terhadap faktor lingkungan dan sosial sekitar perusahaan. Hasil penelitian ini sejalan dengan penelitian yang dilakukan oleh Ramona (2017) yang menyatakan bahwa sebagian besar perusahaan hanya memfokuskan pada faktor tingkat keuangan perusahaan dari pada pengungkapan CSR. Namun penelitian ini tidak sejalan dengan penelitian Armi, dkk (2016). Kesimpulan hipotesis kedua $\left(\mathrm{H}_{2}\right)$ adalah GCG berpengaruh signifikan terhadap nilai perusahaan. GCG yang diberikan oleh perusahaan merupakan sinyal kuat berupa respon positif bagi stakeholders, karena pengelolaan perusahaan sudah baik maka kesejahteraan para investor terjamin. Kepemilikan institusional dapat membuat perusahaan tersebut seakan sedang diawasi oleh para investor baik dari institusi nasional maupun internasional sehingga perusahaan memiliki tanggung jawab dengan saham yang telah diberikan oleh para institusional untuk mengelolah sahamnya dengan baik dan benar, sehingga akan menjadikannya sebuah keuntungan bersama baik bagi kepemilikan institusional maupun perusahaan dan nilai perusahaan meningkat. Hal ini sejalan dengan penelitian Hakim, dkk (2019) yang menyatakan bahwa adanya hubungan signifikan positif GCG terhadap nilai perusahaan hal ini dikarenakan investor akan tertarik melihat nilai GCG yang tinggi dan meyakinkan investor untuk investasi. Namun hal ini tidak sejalan dengan penelitian yang pernah dilakukan oleh Ariani, dkk (2018). Hasil penguji hipotesis ketiga $\left(\mathrm{H}_{3}\right)$ menunjukkan IC tidak berpengaruh signifikan terhadap nilai perusahaan. IC merupakan aset yang pengukuran, peniliannya sulit dilakukan dalam satuan angka, sehingga perusahaan kesulitan untuk mengungkapkan dalam laporan keuangannya. Hasil penelitian ini mendukung Mariani dan Suryani (2018) dan tidak sejalan dengan hasil penelitian Indrawati (2019).

Hasil pengujian hipotesis keempat $\left(\mathrm{H}_{4}\right)$ menyatakan bahwa profitabilitas tidak dapat memoderasi hubungan interaksi antara variabel CSR terhadap nilai perusahaan. Profitabilitas saja tidak cukup untuk meningkatkan nilai perusahaan jika tidak diperkuat dengan laporan kegiatan sosial dan masyarakat pada perusahaan. Pengungkapan tanggung jawab sosial yang tidak konsisten, memberikan sinyal negatif bagi stakeholders dalam menilai perusahaan dan akan berdampak pada pengambilan keputusan yang akan diambil oleh stakeholders. Semakin banyak tanggung jawab sosial yang dilakukan manajemen akan mengurangi perolehan profitabilitas. Hasil penelitian ini tidak sejalan dengan penelitian Nurhayati, dkk (2019). Uji statistic $\mathrm{t}$ menyatakan bahawa profitabilitas terbukti dapat memoderasi hubungan interaksi antara variabel GCG terhadap nilai. Kenaikan nilai GCG suatu perusahaan dapat diartikan bahwa tata kelola perusahaan berjalan dengan baik dan menjalankan prosedur yang telah ditetapkan. Jika perusahaan memiliki nilai GCG yang baik maka perusahaan tersebut dapat meningkatkan suatu keuntungan dan dapat menarik perhatian para invesor untuk berinvestsi di 
perusahaan. Perusahaan yang memiliki nilai GCG tinggi di kepemilikan institusional juga dapat membuat para perusahaan seperti sedang dipantau oleh para investor atau para pemegang saham, sehingga dapat membuat perusahaan lebih meningkatkan kualitas perusahaan agar mendapatkan keuntungan dan dapat membuat para pemegang saham khususnya para pemilik saham institusional merasakan kepuasan karena sahamnya dapat diolah dengan baik, maka dengan begitu nilai perusahaan dapat meningkat lebih baik lagi. Hubungan interaksi variabel moderasi profitabilitas menunjukkan bahwa profitabilitas menjadi cerminan prospek perusahaan di masa mendatang. Dengan adanya penerapan GCG mendorong manajemen melaksanakan tata kelolanya secara maksimal agar profitabilitas perusahaan meningkat. Sinyal yang diberikan perusahaan akan ditangkap oleh stakeholders dan tercermin dalam peningkatan saham perusahaan. Hasil penelitian ini mendukung penelitian Permatasari dan Gayatri (2016). Namun hal ini tidak sejalan dengan hasil penelitian Ariani, dkk (2018). Hipotesis keenam $\left(\mathrm{H}_{6}\right)$ menyatakan bahwa profitabilitas tidak dapat memoderasi hubungan interaksi antara variabel IC terhadap nilai. Pengukuran dan penilaian IC sulit diwujudkan dalam satuan angka sehingga pelaporan luasnya penguasaan perusahaan atas pengetahuan dan teknologi tidak tidak cukup memadai menginformasikan hal tersebut. Tinggi rendahnya nilai IC tidak hanya dapat diukur dari segi profitabilitas saja, melainkan dapat diukur dari segi manajemen. Seperti melakukan pelatihan karyawan yang dilakukan internal perusahaan, memberikan fasilitas yang cukup kepada karyawan agar lebih bertanggung jawab atas tugasnya dan memberikan lingkungan kerja yang bersih dan sehat akan membuat karyawan lebih nyaman untuk bekerja sehingga karyawan akan merasakan puas bekerja dan dapat meningkatkan kontribusi karyawan terhadap perusahaan yang dapat membuat nilai perusahaan semakin baik dengan cara meningkatkan manajemen yang baik dalam perusahaan. Hal ini sejalan dengan penelitian Indrawati (2019) yang menyatakan bahwa profitabilitas terbukti tidak dapat memoderasi hubungan interaksi antara variabel IC terhadap nilai perusahaan karena IC dapat dikelola tidak hanya dengan menggunakan laba dalam perusahaan, tetapi dapat dikelola dengan manajemen yang baik dalam perusahaan. Namun hal ini tidak sejalan dengan hasil penelitian Lestari, dkk (2018).

\section{KESIMPULAN DAN SARAN}

Bagi perusahaan hendaknya lebih memperhatikan sosial lingkungan sekitar perusahaan, agar perusahaan mendapatkan citra yang baik. Penting bagi perusahaan untuk melaporkan setiap kegiatan sosial lingkungan pada laporan sustansibility report untuk menunjang naiknya nilai perusahaan. Dengan melaporkan kegiatan CSR, setiap pemilik saham tentu merasa senang dengan perusahaan dan akan berinvestasi diperusahaan. Selain itu perusahaan harus lebih optimal dalam mengatasi corporate governance. Perusahaan yang bagus dan jujur memiliki nilai GCG tinggi, karena tingginya nilai tersebut perusahaan sudah beroperasi dengan bagus dan optimal. Tinggi rendahnya nilai GCG akan dijadikan sebuah bahan pertimbangan oleh para investor sehingga pihak perusahaan harus memiliki nilai GCG yang tinggi. Selain itu juga perusahaan harus mempertahankan nilai IC dan profitabilitas perusahaan agar nilai perusahaan dapat meningkat secara baik.

\section{DAFTAR PUSTAKA}

Amini, Aisyah. 2018. Pengaruh Program Corporate Social Responsibility (CSR) Terhadap Peningkatan Kesejahteraan Masyarakat Dalam Perspektif Ekonomi Islam (Studi Pada Implementasi CSR PT. Pertamina Geothermal Energy (PGE) Desa Pagar Alam dan Desa Ngarip Kecamatan Ulubelu Kabupa. 2, 227-249.

Ariani, Rida., Sitawati, Riana., dan Sam'ani. 2018. Pengaruh Pengungkapan CSR dan GCG 
Terhadap Nilai Perusahaan dengan Profitabilitas Sebagai Variabel Moderasi. 9(1), 3847.

Hadiwijaya, Rendy. 2019. Pengaruh Intellectual Capital Pada Nilai Perusahaan Dengan Kinerja Keuangan Sebagai Variabel Intervening. E-Jurnal Akuntansi, 1717.

Hakim, L. N., Lestari, Sri., Widiastuti, E., Dewi, M. K. 2019. Pengaruh Pengungkapan Corporate Social Responsibility dan Good Corporate Governance Terhadap Nilai Perusahaan Dengan Profitabilitas Sebagai Variabel Pemoderasi. Jurnal Pro Bisnis, Vol. 12(2), 25-32.

Indrawati, Yuli. 2019. Pengaruh Intellectual Capital dan Pengungkapan Sustainability Report Terhadap Nilai Perusahaan dengan Profitabilitas Sebagai Variabel Moderasi. Implementation Science, 39(1), 1-15.

Juwita, R.akhmini, \& Angela, Aurora. 2016. Pengaruh Intellectual Capital Terhadap Nilai Perusahaan pada Perusahaan Indeks Kompas 100 di Bursa Efek Indonesia. Jurnal Akuntansi. Vol. 8(1), 1-15.

Lestari, Dyah A D dan Satyawan, Made D. 2018. Pengaruh Intellectual Capital Terhadap Nilai Perusahaan Dengan Profitabilitas Sebagai Variabel Moderasi. Jurnal Akuntansi. Universitas Negeri Surabaya.

Mariani, Desy. dan Suryani. 2018. Pengaruh Enterprise Risk Management Disclosure dan Corporate Social Responsibility Disclosure Terhadap Nilai Perusahaan Dengan Profitabilitas Sebagai Variabel Pemoderasi (Studi Empiris Pada Perusahaan Sektor Industri Barang Konsumsi di Bursa Efek Indonesia Tahun 2012 - 2016. Jurnal Akuntansi Dan Keuangan, 7(2), 119-138.

Nurhayati, I., Poerwati, T., Kartika, A., Akuntansi, P. S., Stikubank, U., \& Perusahaan, N. 2019. Dampak Moderasi Profitabilitas dan Leverage Terhadap Pengaruh CSR Pada Nilai Perusahaan di Indonesia. Prosiding SENDI_U 2019, 978-979.

Novita, Rizki. 2018. Pengaruh Corporate Social Responsibility dan Good Corporate Governance Terhadap Nilai Perusahaan Dengan Kinerja Keuangan Sebagai Variabel Intervening (Studi Pada Perusahaan Indonesia yang Terdaftar di LQ45 Tahun 20132016). Journal of Chemical Information and Modeling, 53(9), 1689-1699.

Permatasari, L. W dan Gayatri. 2016. Profitabilitas Sebagai Pemoderasi Pengaruh Good Corporate Governance Pada Nilai Perusahaan. E-Jurnal Akuntansi. ISSN: 2302-8559, 2307-2335.

Ramona, Suci. 2017. Pengaruh Corporate Social Responsibility Terhadap Nilai Perusahaan Dengan Profitabilitas Sebagai Variabel Moderating (Studi Empiris Perusahaan Sektor Pertambangan yang Terdaftar di Bursa Efek Indonesia Periode 2011-2015). 1-14. 